\title{
Radiological Emergency Preparedness: A Survey of Nuclear Medicine Technologists in the United States
}

\author{
Miriam E. Van Dyke ${ }^{1}$, Lisa C. McCormick ${ }^{2}$, Norman E. Bolus ${ }^{1}$, Jesse Pevear III ${ }^{3}$, and Ziad N. Kazzi ${ }^{4}$ \\ ${ }^{1}$ Department of Clinical and Diagnostic Sciences, School of Health Professions, University of Alabama at Birmingham, Birmingham, \\ Alabama; ${ }^{2}$ Department of Health Care Organization and Policy, School of Public Health, University of Alabama at Birmingham, \\ Birmingham, Alabama; ${ }^{3}$ Survey Research Unit, School of Public Health, University of Alabama at Birmingham, Birmingham, \\ Alabama; and ${ }^{4}$ Department of Emergency Medicine, Emory University, Atlanta, Georgia
}

Because of the increasing risk of radiological emergencies, public health agencies and first-response organizations are working to increase their capability of responding. Nuclear medicine technologists (NMTs) have expertise in certain areas, such as radiation safety, radiobiology, decontamination, and the use of radiation detection and monitoring equipment, that could be useful during the response to events that involve radiological materials. Methods. To better understand the potential role that NMTs may have in response efforts, a cross-sectional survey was conducted. The survey was sent electronically to the 7,000 members of the Technology Section of the Society of Nuclear Medicine and Molecular Imaging. Eight hundred fifty NMTs responded to the survey, for a response rate of $12.14 \%$. The study queried NMTs across the United States on their knowledge of using radiation detection and monitoring equipment, such as a scintillation $\gamma$-cameras, Geiger counters, thyroid probes, well counters, and portal monitors; willingness to participate in response efforts during a nuclear reactor accident, nuclear weapon detonation, or dirty bomb detonation; access to radiation detection and monitoring equipment within their work setting; familiarity with current preparedness guidance and tools provided by the Centers for Disease Control and Prevention and U.S. Department of Health and Human Services; and registration in volunteer initiatives such as the Emergency System for Advance Registration of Volunteer Health Professionals, Metropolitan Medical Response System, and Medical Reserve Corps. Results. Survey results suggest that NMTs are knowledgeable and willing to respond to radiological emergencies, regardless of number of years of work experience. Radiological preparedness training within the last 5 y significantly increases NMTs' willingness to respond and familiarity with current guidance and tools provided by the Centers for Disease Control and Prevention and Department of Health and Human Services. Respondents reported a low participation level in volunteer programs, and most agreed that continuing education should include radiological emergency preparedness. Conclusion. NMTs should be considered an untapped resource and should be strategically recruited for involvement in radiological emergency preparedness planning and training. NMTs should also

\footnotetext{
Received Apr. 12, 2013; revision accepted Jun. 18, 2013.

For correspondence or reprints contact: Miriam E. Van Dyke, University of Alabama at Birmingham, 200 Knoxville Lane, Oxford, AL 36203.

E-mail: mirm@uab.edu

Published online Aug. 1, 2013.

COPYRIGHT (C 2013 by the Society of Nuclear Medicine and Molecular Imaging, Inc.
}

consider becoming involved in local volunteer initiatives because they have the knowledge and willingness to provide assistance during a radiological emergency.

Key Words: emergency; nuclear medicine technologists; radiological; preparedness

J Nucl Med Technol 2013; 41:223-230

DOI: 10.2967/jnmt.113.124677

\section{$\mathbf{R}$} adiological emergency preparedness has been gaining increased attention due to recent events such as the 2011 Fukushima Daiichi nuclear emergency (1-3), which revealed a shortage of experts in the field of radiation and radionuclide detection (4). In the United States, public health agencies and first-response organizations are experiencing the same issue and are beginning to build partnerships to expand their capability to respond to emergencies involving radioactive materials (4-8).

Medical personnel, particularly nuclear medicine technologists (NMTs), are a source of radiological expertise that can be utilized during a public health crisis involving radioactive materials. NMTs are a valuable resource because of their knowledge and daily dealings with radioactive materials, and the education of NMTs in health physics, radiation biology, radiation safety, decontamination, and patient care can be helpful during a radiological emergency $(8,9)$. NMTs can participate as part of a local radiological emergency response team. In this capacity, an NMT can provide expertise to assist with radiological dose assessments, population monitoring, development of radiological emergency response plans, and determination of the extent of contamination (8). NMTs who work in a hospital setting can also serve as a resource to their hospital when it is planning for and responding to a radiological emergency. There is a significant need for training and informational resources tailored to a hospital setting (10), and NMTs can assist in developing these resources and in training hospital staff.

Previous studies have assessed health care professionals' willingness, comfort, and knowledge in responding to a radiological event $(5,6,11)$. In 2007, a survey conducted in Canada of prehospital providers, that is, emergency medical 
technicians and paramedics, indicated that " $22 \%$ of 640 respondents did not recall receiving training within the past year for chemical, biological, radiological, and nuclear events" (6). Respondents also felt much more prepared for a mass casualty, chemical, and biological event than a radiation/ nuclear event (6). Sheikh et al. found in a 2011 survey of emergency medicine residents and faculty that only $37 \%$ of the 62 resident respondents and $28 \%$ of the 51 faculty respondents "had attended radiological preparedness training in the preceding 5 years or any training in radiation detection." Compared with their untrained counterparts, those with training were more familiar with the medical countermeasures DTPA (diethylenetriaminepentaacetic acid) and Prussian blue, which can be used in the event of internal contamination with certain radioactive materials; were more comfortable assessing patients for acute radiation syndrome and internal contamination; were more familiar with decontamination procedures and management of victims of radiation incidents; and were more comfortable using radiation detection equipment (5). Because health care professionals would receive patients needing care during a radiological emergency, it is imperative that they have proper and ongoing continuing education in this area to deliver care effectively.

Volunteer agencies can be a resource during the response to a radiological emergency. However, enrollment in volunteer networks, such as the Medical Reserve Corps (MRC), is not automatically predictive of willingness to respond to all types of public health emergencies. A 2013 study by Errett et al. indicated that MRC volunteers are consistently less willing to respond to radiological emergencies than to other types of emergencies such as natural disasters. Those volunteers with higher self-efficacy, which can equate to increased knowledge and comfort in a certain subject matter area, were more willing to respond (12). NMTs can potentially serve to fill this volunteer gap during an emergency by becoming subject matter experts in the area of radiobiology, radiological detection, and dose assessment.

The purpose of this study was to assess the willingness and knowledge of NMTs to participate in radiological emergency preparedness and response operations and to determine what radiation detection, measuring, and imaging equipment they would have access to during an event at their workplace. The study also assessed whether years of work experience or past radiological emergency preparedness training had an effect on willingness and knowledge and if equipment availability varies by NMT work setting. Respondents were asked about the use of each of the following: scintillation $\gamma$-cameras, well counters, Geiger counters, thyroid probes, portal monitors, and portable multichannel analyzers.

A scintillation $\gamma$-camera, commonly found in nuclear medicine departments in both inpatient and outpatient medical centers, can be used to detect and characterize internal contamination (13). Also, a scintillation $\gamma$-camera has the potential to act as a multichannel analyzer to discern radionuclides based on the energy spectrum detected. Well counters and portable multichannel analyzers, both of which are capable of discerning energy spectrums, are used to detect external and internal contamination, whether by a wipe survey or by a urine or blood bioassay. Geiger counters, which are handheld pieces of equipment with a probe, are useful to detect external and possibly internal contamination of individuals or external contamination of surfaces with $\gamma$ and $\beta$-particle-emitting radionuclides. Geiger counters are found in nuclear medicine departments, in many research labs, and in other facilities and organizations because of the requirements of the United States Nuclear Regulatory Commission (14-16). Thyroid probes are useful in the detection of radioactive forms of iodine, which have escaped in past nuclear power plant emergencies $(17,18)$. Portal monitors are devices that check for radioactive contamination on individuals or vehicles as they walk or drive through, respectively. They are best used in "community reception centers or in entrances to critical structures (such as hospitals... airports, train and bus terminals)" and are used for the detection of $\beta$ - and $\gamma$-radiation (19). Although portal monitors are not commonly found in nuclear medicine departments, they are useful in surveying a large number of people for contamination with radioactive material (20).

\section{MATERIALS AND METHODS}

A 28-question survey (Appendix A) was developed assessing NMTs' knowledge about radiological emergency preparedness and willingness to participate in a response to an emergency. NMTs' knowledge of radiation protection principles was assessed, along with knowledge of the characteristics specific to $\alpha-, \beta$-, and $\gamma$-emitting radionuclides. The survey also evaluated access to certain types of equipment that have the potential to be useful in a response to radiological events $(13,20-23)$. NMTs' familiarity with preparedness resources was determined. These resources included the Centers for Disease Control and Prevention (CDC) guidance titled, "Use of Radiation Detection, Measuring, and Imaging Instruments to Assess Internal Contamination from Intakes of Radionuclides (21)," and the U.S. Department of Health and Human Services Radiation Emergency Medical Management (REMM) Web portal (24). NMTs were also asked about their current registration status in volunteer initiatives such as the Emergency System for Advance Registration of Volunteer Health Professionals (ESAR-VHP), the Metropolitan Medical Response System (MMRS), and the MRC. Finally, NMTs were asked if they had participated in continuing education in radiological emergency procedures in the last $5 \mathrm{y}$ and if Verification of Involvement in Continuing Education (VOICE) or other continuing education programs included training on radiological emergency preparedness and response.

Internal Review Board approval was obtained before the distribution of the survey (protocol E120224010). The survey was distributed electronically via SurveyMonkey to 7,000 NMTs from across the United States using the Society of Nuclear Medicine and Molecular Imaging Technologist Section e-mail database. The survey was distributed in July 2012 and was open for 6 wk. A reminder e-mail was sent approximately $3 \mathrm{wk}$ after the start date of the survey.

Demographic information including the credentials, regional location, years of experience, work setting, work facility preparedness, and recentness of radiation emergency preparedness training was collected. All responses were anonymous. 
TABLE 1

Descriptive Variables

\begin{tabular}{|c|c|c|}
\hline Variable & Description & $n$ \\
\hline \multirow[t]{3}{*}{ Credentials $(n=846)$} & Certified (NMTCB or ARRT) & $833(98.46 \%)$ \\
\hline & Other & $13(1.54 \%)$ \\
\hline & Missing & 4 \\
\hline \multirow[t]{5}{*}{ Region of United States $(n=832)$} & Northeast & $334(40.14 \%)$ \\
\hline & Northwest & $117(14.06 \%)$ \\
\hline & Southeast & $222(26.68 \%)$ \\
\hline & Southwest & $159(19.11 \%)$ \\
\hline & Missing & 18 \\
\hline \multirow[t]{3}{*}{ Years of work experience $(n=847)$} & $<20$ y & $364(42.98 \%)$ \\
\hline & $\geq 20$ y & $483(57.02 \%)$ \\
\hline & Missing & 3 \\
\hline \multirow[t]{5}{*}{ Work setting $(n=841)$} & Academia & $51(6.06 \%)$ \\
\hline & Hospital & $502(59.69 \%)$ \\
\hline & Outpatient center & $166(19.74 \%)$ \\
\hline & Other & $122(14.51 \%)$ \\
\hline & Missing & 9 \\
\hline \multirow{3}{*}{$\begin{array}{l}\text { Has the facility in which you work adopted } \\
\text { and implemented an emergency } \\
\text { preparedness plan that includes } \\
\text { radiological disaster preparedness? }(n=836)\end{array}$} & Yes & $514(61.48 \%)$ \\
\hline & No & $322(38.52 \%)$ \\
\hline & Missing & 14 \\
\hline \multirow{3}{*}{$\begin{array}{l}\text { Have you attended radiation emergency } \\
\text { preparedness training in the last } 5 \text { y? }(n=839)\end{array}$} & Yes & $296(35.28 \%)$ \\
\hline & No & $543(64.72 \%)$ \\
\hline & Missing & 11 \\
\hline \multicolumn{3}{|l|}{ Equipment availability } \\
\hline \multirow[t]{3}{*}{ Scintillation $\gamma$-camera $(n=832)$} & Yes & $758(91.11 \%)$ \\
\hline & No & $74(8.89 \%)$ \\
\hline & Missing & 18 \\
\hline \multirow[t]{3}{*}{ Well counter $(n=832)$} & Yes & $715(85.94 \%)$ \\
\hline & No & $117(14.06 \%)$ \\
\hline & Missing & 18 \\
\hline \multirow[t]{3}{*}{ Geiger counter $(n=837)$} & Yes & $810(96.77 \%)$ \\
\hline & No & $27(3.23 \%)$ \\
\hline & Missing & 13 \\
\hline \multirow[t]{3}{*}{ Thyroid probe $(n=817)$} & Yes & $535(65.48 \%)$ \\
\hline & No & $282(34.52 \%)$ \\
\hline & Missing & 33 \\
\hline \multirow[t]{3}{*}{ Portal monitor $(n=782)$} & Yes & $148(18.93 \%)$ \\
\hline & No & $634(81.07 \%)$ \\
\hline & Missing & 68 \\
\hline \multirow[t]{3}{*}{ Portable multi-channel analyzer $(n=790)$} & Yes & $173(21.90 \%)$ \\
\hline & No & $617(78.10 \%)$ \\
\hline & Missing & 60 \\
\hline
\end{tabular}

Univariate analysis was used to describe the study population. $\chi^{2}$ analysis was used to test for differences between the knowledge and willingness of NMTs with different levels of experience and training. Experience was defined using either 1 of 2 levels: those with less than $20 \mathrm{y}$ of work experience or those with $20 \mathrm{y}$ or more of work experience. All analyses were performed using SAS, version 9.3 (SAS Institute Inc.). An $\alpha$-value of 0.05 was used to determine significance.

\section{RESULTS}

There were 850 NMTs who responded to the survey, for a response rate of $12.14 \%$.

Most respondents $(98.46 \%, n=833)$ were certified by either the Nuclear Medicine Technology Certification
Board (NMTCB) or the American Registry of Radiological Technologists (ARRT). Most respondents were from the northeastern United States $(40.14 \%, n=334)$, had $20 \mathrm{y}$ or more of work experience $(57.02 \%, n=483)$, and worked in a hospital setting $(59.69 \%, n=502)$. Over $61 \%(n=$ 514) of the respondents reported that their workplace had adopted and implemented an emergency preparedness plan that included radiological emergency preparedness. However, only $35.28 \%(n=296)$ reported having participated in any radiation emergency preparedness training in the last $5 \mathrm{y}$ (Table 1). The descriptive data for the availability of equipment to NMTs is also presented in Table 1. 
TABLE 2

Radiation Detection, Monitoring, and Imaging Equipment Availability by Work Setting

\begin{tabular}{|c|c|c|c|c|c|c|}
\hline Setting & $\begin{array}{l}\text { Scintillation } \\
\gamma \text {-camera }\end{array}$ & Well counter & Geiger counter & Thyroid probe & Portal monitor & $\begin{array}{c}\text { Portable multichannel } \\
\text { analyzer }\end{array}$ \\
\hline Academia & $28(57.14 \%)$ & $37(74.00 \%)$ & 46 (92.00\%) & 31 (63.27\%) & $12(25.53 \%)$ & $16(34.04 \%)$ \\
\hline Hospital & 495 (99.40\%) & 455 (91.55\%) & 499 (100.00\%) & $420(85.37 \%)$ & $113(24.25 \%)$ & $130(27.54 \%)$ \\
\hline Outpatient center & 147 (90.74\%) & $134(82.21 \%)$ & $163(98.79 \%)$ & $36(23.08 \%)$ & $10(6.45 \%)$ & $8(5.16 \%)$ \\
\hline Other & $83(70.34 \%)$ & 85 (73.28\%) & 97 (82.91\%) & $45(39.13 \%)$ & $12(11.01 \%)$ & $19(17.12 \%)$ \\
\hline
\end{tabular}

Data are number of devices.

In Table 2, equipment availability by work setting (i.e., academia, hospital, outpatient center, and other) is presented. NMTs working in hospital and outpatient center settings are more likely to have access to a scintillation $\gamma$-camera, a well counter, and a Geiger counter. Those working in hospitals or academia are more likely to have access to a thyroid probe, a portal monitor, and a portable multichannel analyzer. (Table 2.)

NMTs were also asked questions to determine their knowledge of the use of radiation detection and monitoring equipment during a response to a radiological event. Those NMTs with less than $20 \mathrm{y}$ of work experience were significantly more knowledgeable of the type of radiation that could be detected by a scintillation $\gamma$-camera $(P=$ $0.0021)$ and a well counter $(P=0.0108)$. However, there were no significant differences in knowledge of the use of Geiger counters $(P=0.109)$, thyroid probes $(P=0.3144)$, or portal monitors $(P=0.0665)$ based on years of work experience (Table 3 ).

Only $26.6 \%$ ( $n=218)$ of respondents reported receiving continuing education-including VOICE or other continuing education programs - that covered radiological emergency preparedness and response. However, most respondents (97.9\%, $n=816)$ agreed that continuing education programs should include such training. Most respondents $(77.27 \%$, $n=646$ ) were not familiar with the U.S. Department of Health and Human Services REMM Web portal resource, and $77.10 \%(n=643)$ were not familiar with the CDC guidance titled, "Use of Radiation Detection, Measuring, and Imaging Instruments to Assess Internal Contamination from Intakes of Radionuclides" (Table 4).
Even though NMTs have knowledge and abilities that would be useful during a radiological response, the responses indicate that only $2.14 \%(n=18)$ are registered to volunteer via the ESAR-VHP, only $1.0 \%(n=8)$ are a registered member of the MMRS, and only $2.2 \%(n=$ 18) are members of an MRC (Table 4).

Table 5 examines familiarity with both REMM and the CDC guidance documents and the differences between NMTs who reported having radiological preparedness training in the last $5 \mathrm{y}$ and those who had not. Also, the influence that training has on an NMT's willingness to respond to a nuclear reactor accident, a nuclear weapon detonation, and a dirty bomb detonation was included. As shown in Table 5, attending radiological preparedness training in the last 5 y was significantly associated with increased familiarity with REMM and CDC guidance documents as well as increased willingness to respond to a nuclear reactor accident $(P=0.0002)$, a nuclear weapon detonation $(P=$ $0.0014)$, and a dirty bomb detonation $(P=0.0001)$.

\section{DISCUSSION}

Overall, most respondents reported having access to a scintillation $\gamma$-camera, a well counter, a Geiger counter, and a thyroid probe. During a radiological disaster, NMTs working in hospital and outpatient center settings are highly likely to have access to a scintillation $\gamma$-camera, a well counter, and a Geiger counter. If a thyroid probe is needed during a response, an NMT working in a hospital is most likely to have access to this piece of equipment. Portal monitors and portable multichannel analyzers are not commonly available to NMTs.

TABLE 3

Knowledge of the Use of Equipment in a Radiological Response by Years of Work Experience

\begin{tabular}{lccccccc}
\hline & \multicolumn{2}{c}{$<20$ y of work experience $(n)$} & & \multicolumn{2}{c}{$\geq 20$ y of work experience $(n)$} & \\
\multicolumn{1}{c}{ Equipment } & Yes & No & & Yes & No & $\chi^{2}$ & $P$ \\
\hline Scintillation $\gamma$-camera $(n=839)$ & $268(74.44 \%)$ & $92(25.56 \%)$ & & $309(64.51 \%)$ & $170(35.49 \%)$ & 9.4463 & 0.0021 \\
Well counter $(n=833)$ & $129(36.34 \%)$ & $226(63.66 \%)$ & & $134(28.03 \%)$ & $344(71.97 \%)$ & 6.5028 & 0.0108 \\
Geiger counter $(n=837)$ & $212(58.56 \%)$ & $150(41.44 \%)$ & & $304(64.00 \%)$ & $171(36.00 \%)$ & 2.5681 & 0.1090 \\
Thyroid probe $(n=837)$ & $349(96.94 \%)$ & $11(3.06 \%)$ & & $456(95.60 \%)$ & $21(4.40 \%)$ & 1.0123 & 0.3144 \\
Portal monitor $(n=810)$ & $196(55.06 \%)$ & $160(44.94 \%)$ & & $279(61.45 \%)$ & $175(38.55 \%)$ & 3.3673 & 0.0665 \\
\hline
\end{tabular}


TABLE 4

Continuing Education, Familiarity with Preparedness Materials, and Volunteer Programs

\begin{tabular}{|c|c|c|c|}
\hline Continuing education and preparedness materials & Yes $(n)$ & No $(n)$ & Missing $(n)$ \\
\hline $\begin{array}{l}\text { Does VOICE or other continuing education programs include training for } \\
\text { radiological disaster procedures? }(n=821)\end{array}$ & $218(26.6 \%)$ & $603(73.4 \%)$ & 29 \\
\hline $\begin{array}{l}\text { Are you familiar with the REMM program provided by the U.S. Department } \\
\text { of Health and Human Services? }(n=836)\end{array}$ & $190(22.7 \%)$ & $646(77.3 \%)$ & 14 \\
\hline $\begin{array}{l}\text { Are you familiar with the CDC's guidance titled, "Use of Radiation } \\
\text { Detection, Measuring, and Imaging Instruments to Assess Internal } \\
\text { Contamination from Intakes of Radionuclides?" }(n=834)\end{array}$ & $191(22.9 \%)$ & $643(77.1 \%)$ & 16 \\
\hline \multicolumn{4}{|l|}{$\begin{array}{l}\text { Are you a member or have you signed up to volunteer through any of the } \\
\text { following? }\end{array}$} \\
\hline ESAR-VHP $(n=840)$ & $18(2.1 \%)$ & $822(97.9 \%)$ & 10 \\
\hline $\operatorname{MMRS}(n=833)$ & $8(1.0 \%)$ & $825(99.0 \%)$ & 17 \\
\hline $\operatorname{MRC}(n=835)$ & $18(2.2 \%)$ & $817(97.8 \%)$ & 15 \\
\hline
\end{tabular}

It is expected that those who work in the nuclear medicine field should have knowledge of the use of a scintillation $\gamma$-camera and a thyroid probe. Further, NMTs should be able to use a well counter to determine whether an individual is internally contaminated with either $\alpha$ - or $\gamma$-radiation. It appears that years of work experience in the nuclear medicine field did not increase the NMT's knowledge of the use of these pieces of equipment in a radiological emergency. In fact, in some instances, those with less than $20 \mathrm{y}$ of work experience had significantly more knowledge. One reason this may be true is because nuclear medicine curricula have expanded over the years to include procedures that may be useful in a radiological response. Further examination of NMT curricula and their radiological preparedness content is a possible area for future study.

Continuing education for NMTs seems to include little training on radiological emergency preparedness and response. Only $26.6 \%$ of respondents reported having any continuing education that included such content, and only $35.3 \%$ reported having any emergency preparedness training in the last $5 \mathrm{y}$. Continuing education and training that include radiological emergency preparedness and response should be considered in the future.

Most NMT respondents were not familiar with the U.S. Department of Health and Human Service's REMM program, nor were they familiar with the CDC guidance document, "Use of Radiation Detection, Measuring, and Imaging Instruments to Assess Internal Contamination from Intakes of
Radionuclides." Respondents who reported receiving radiological training were significantly more familiar with both REMM $(P<0.0001)$ and the CDC guidance document $(P<0.0001)$. This fact makes the case that future continuing education and training should include introducing NMTs to these resources to increase their familiarity and understanding of how these resources can be of benefit during a response.

With an increased emphasis on the need for states to prepare for radiological emergencies, it can be seen that NMTs are an untapped resource. Few respondents are registered in ESAR-VHP, participate in an MMRS, or are members of an MRC. Public health agencies should consider recruiting needed expertise from this rich source of knowledge and willingness to respond.

It appears that NMTs are willing to assist in the response to events such as nuclear reactor accidents, nuclear weapon detonations, and dirty bomb detonations. However, having attended training in the last $5 \mathrm{y}$ significantly increased respondents' willingness to respond to a nuclear reactor accident, nuclear weapon detonation, and dirty bomb detonation. Again, this finding emphasizes the need for training that includes radiological emergency preparedness and response procedures.

\section{CONCLUSION}

The initial response to a radiological emergency may include radiation detection, population monitoring, decontamination, and dose assessment. Knowledgeable, willing,

TABLE 5

Differences in Familiarity and Willingness to Respond by Radiological Preparedness Training

\begin{tabular}{|c|c|c|c|c|c|c|c|}
\hline \multirow[b]{2}{*}{ Parameter } & \multicolumn{2}{|c|}{ No training in the last $5 \mathrm{y}$} & \multicolumn{2}{|c|}{ Training within the last $5 \mathrm{y}$} & \multirow[b]{2}{*}{ Missing $(n)$} & \multirow[b]{2}{*}{$x^{2}$} & \multirow[b]{2}{*}{$P$} \\
\hline & Yes $(n)$ & No $(n)$ & Yes $(n)$ & No $(n)$ & & & \\
\hline Familiarity with REMM $(n=834)$ & $69(12.78 \%)$ & $471(87.22 \%)$ & $120(40.82 \%)$ & $174(59.18 \%)$ & 16 & 85.3880 & $<0.0001$ \\
\hline Familiarity with CDC guidance $(n=832)$ & $81(15.03 \%)$ & $458(84.97 \%)$ & $109(37.20 \%)$ & $184(62.80 \%)$ & 18 & 52.9616 & $<0.0001$ \\
\hline \multicolumn{8}{|l|}{ Willingness to respond to... } \\
\hline Nuclear reactor accident $(n=768)$ & $404(84.70 \%)$ & $73(15.30 \%)$ & $276(94.85 \%)$ & $15(5.15 \%)$ & 82 & 14.1516 & 0.0002 \\
\hline Nuclear weapon detonation $(n=825)$ & 437 (82.14\%) & $95(17.86 \%)$ & $265(90.44 \%)$ & $28(9.56 \%)$ & 25 & 10.2620 & 0.0014 \\
\hline Dirty bomb detonation $(n=831)$ & $451(83.83 \%)$ & $87(16.17 \%)$ & $273(93.17 \%)$ & $20(6.83 \%)$ & 19 & 14.7670 & 0.0001 \\
\hline
\end{tabular}


and prepared individuals will be needed to assist with a response of this nature. Public health agencies will need to coordinate with NMTs and draw on their expertise and knowledge to strengthen the community's capability of responding to a radiological or nuclear emergency. Public health agencies and first-response organizations are working to build the capacity to respond to emergencies involving radiological materials. It is important that NMTs be included in preparedness efforts and recruited to volunteer through programs such as MMRS, MRC, and ESAR-VHP.

Efforts to include radiological response procedures in NMT continuing education and training should be examined. There are apparent gaps in NMTs' knowledge and familiarity with response resources. Therefore, it is suggested that radiological emergency preparedness courses be designed for appropriate continuing education credit for NMTs. This step is becoming increasingly important as this study and others show that training increases the willingness to respond (5).

Hospitals should consider capitalizing on their NMT staff's knowledge and willingness to help with planning and training efforts within the hospital. This measure can help fill gaps in a hospital's planning and ability to respond to patients contaminated with radiological materials.

Ultimately, communities are trying to increase the ability of the public health system to handle radiological events of any nature. To do so effectively, they need to identify and coordinate with their own members who have existing expertise. NMTs are a perfect example of an untapped resource that public health agencies can recruit to assist with these important issues.

\section{APPENDIX A}

\section{Survey Questionnaire}

1. Which of the following best explains your credentials as a Nuclear Medicine Technologist? (Select one)

- Certified (NMTCB or ARRT)

- Noncertified

- "Grandfathered in"

- Other

2. In which region of the United States are you located? (Select one)

- Northeast

- Northwest

- Southeast

- Southwest

3. How many years of nuclear medicine experience do you have? (Select one)

- 0-5 years

- 5-10 years

- 10-15 years

- 15-20 years

- $20+$ years

4. Which of the following best explains the setting in which you work as a Nuclear Medicine Technologist? (Select one)
- Academia

- Hospital

- Outpatient Center

- Other

5. You are a part of a response team during a radiological disaster. Would you be comfortable performing the following procedure in order to assess patients for radioactive contamination?

- Scintillation gamma camera scan (Yes/No)

- Urine bioassay using a well counter (Yes/No)

- Geiger counter survey (Yes/No)

- Thyroid probe uptake (Yes/No)

- Portal monitor (Yes/No)

- Portable multichannel analyzer (Yes/No)

6. Would you like to learn more about the following procedure in order to assess patients for radioactive contamination?

- Scintillation gamma camera scan (Yes/No)

- Urine bioassay using a well counter (Yes/No)

- Geiger counter survey (Yes/No)

- Thyroid probe uptake (Yes/No)

- Portal monitor (Yes/No)

- Portable multichannel analyzer (Yes/No)

7. Is the following equipment available for use in your department?

- Scintillation gamma camera (Yes/No)

- Well counter (Yes/No)

- Geiger counter (Yes/No)

- Thyroid probe (Yes/No)

- Portal monitor (Yes/No)

- Portable multichannel analyzer (Yes/No)

8. Are you comfortable in performing the decontamination of radiological disaster victims in the event of a radiological disaster? (Yes/No)

9. A regular urine bioassay using a well counter can test for internal contamination of which of the following ionizing radiation? (Select one)

- Gamma radiation

- Low-energy alpha radiation

- Neither low-energy alpha nor gamma radiation

- Both low-energy alpha and gamma radiation

10. A scintillation gamma-camera is best used for which of the following during a radiological disaster? (Select one)

- To scan a large amount of people for possible radiation exposure

- To identify unknown internal radiation contamination

- To assess radioiodine uptake

- To assess the radiation exposure rate of an area or patient

11. A Geiger counter is best used for which of the following during a radiological disaster? (Select one)

- To scan a large amount of people for possible radiation exposure

- To identify unknown internal radiation contamination

- To assess radioiodine uptake

- To assess the radiation exposure rate of an area or patient 
12. A thyroid probe is best used for which of the following during a radiological disaster? (Select one)

- To scan a large amount of people for possible radiation exposure

- To identify unknown internal radiation contamination

- To assess radioiodine uptake

- To assess the radiation exposure rate of an area or patient

13. A portal monitor is best used for which of the following during a radiological disaster? (Select one)

- To scan a large amount of people for possible radiation exposure

- To identify unknown internal radiation contamination

- To assess radioiodine uptake

- To assess the radiation exposure rate of an area or patient

14. You are part of a response team during a radiological disaster. The radioactive emissions from ${ }^{137} \mathrm{Cs}$ contamination are best shielded against with which of the following? (Select one)

- Air

- Lead $(\mathrm{Pb})$

- Plexiglas

- Concrete

- Plastic lined lead container

15. You are a part of a response team during a radiological disaster. The radioactive emissions from Plutonium-239 and/or Uranium-235 are best shielded against with which of the following? (Select one)

- Air

- Lead $(\mathrm{Pb})$

- Plexiglas

- Concrete

- Plastic lined lead container

16. You are a part of a response team during a radiological disaster. The radioactive emissions from ${ }^{131}$ I contamination are best shielded against with which of the following? (Select one)

- Air

- Lead $(\mathrm{Pb})$

- Plexiglas

- Concrete

- Plastic lined lead container

17. You are a part of a response team during a radiological disaster. The radioactive emissions from Phosphorus-32 contamination are best shielded against with which of the following? (Select one)

- Air

- Lead $(\mathrm{Pb})$

- Plexiglas

- Concrete

- Plastic lined lead container

18. In the event of a nuclear reactor accident, are you willing to assist with radiation detection/monitoring at your facility? (Yes/No)

19. In the event of a nuclear weapon detonation, are you willing to assist with radiation detection/monitoring at your facility? (Yes/No)
20. In the event of a dirty bomb detonation, are you willing to assist with radiation detection/monitoring at your facility? (Yes/No)

21. As a professional with a nuclear medicine background, do you feel prepared to work as a part of a response team in a hospital setting during a radiological disaster? (Yes/No)

22. Has the facility in which you work adopted and implemented an emergency preparedness plan that includes radiological disaster preparedness? (Yes/No)

23. Do you think continuing education programs should include training for radiological disaster procedures? (Yes/ No)

24. Have you received radiological disaster preparedness training within the last 5 years? (Yes/No)

25. Does VOICE (Verification Of Involvement In Continuing Education) or other continuing education programs include training for radiological disaster procedures? (Yes/ No)

26. Are you familiar with the REMM (Radiation Emergency Medical Management) program provided by the U.S. Department of Health \& Human Services? (Yes/No)

27. Are you familiar with the Centers for Disease Control and Prevention guidance titled, "Use of Radiation Detection, Measuring, and Imaging Instruments to Assess Internal Contamination from Intakes of Radionuclides," which is located at http://www.bt.cdc.gov/radiation/clinicians/evaluation/index.asp? (Yes/No)

28. Are you a member and/or have you signed up to volunteer through any of the following?

- Emergency System for Advance Registration of Volunteer Health Professionals (ESAR-VHP) (Yes/No)

- Metropolitan Medical Response System (MMRS) (Yes/No)

- Medical Reserve Corps (MRC) (Yes/No)

\section{DISCLOSURE}

No potential conflict of interest relevant to this article was reported.

\section{REFERENCES}

1. Tsubokura M, Gilmour S, Takahashi K, Oikawa T, Kanazawa Y. Internal radiation exposure after the Fukushima nuclear power plant disaster. JAMA. 2012;308: 669-670.

2. Miller K, Groff L, Erdman M, King S. Lessons learned in preparing to receive large numbers of contaminated individuals. Health Phys. 2005;89(2, suppl)S42S47.

3. Bushberg JT, Kroger LA, Hartman MB, et al. Nuclear/radiological terrorism: emergency department management of radiation casualties. J Emerg Med. 2007; 32:71-85.

4. Miller CW. The Fukushima radiological emergency and challenges identified for future public health responses. Health Phys. 2012;102:584-588.

5. Sheikh S, McCormick LC, Pevear J, Adoff S, Walter FG, Kazzi ZN. Radiological preparedness-awareness and attitudes: a cross-sectional survey of emergency medicine residents and physicians at three academic institutions in the United States. Clin Toxicol (Phila). 2012;50:34-38.

6. Chaput CJ, Deluhery MR, Stake CE, Martens KA, Cichon ME. Disaster training for prehospital providers. Prehosp Emerg Care. 2007;11:458-465.

7. Jakeway CC, LaRosa G, Cary A, Schoenfisch S; Association of State and Territorial Directors of Nursing. The role of public health nurses in emergency preparedness and response: a position paper of the Association of State and Territorial Directors of Nursing. Public Health Nurs. 2008;25:353-361. 
8. Miller CW, Whitcomb RC, Ansari A, McCurley C, Guinn A, Tucker F. The roles of medical health physicists in a medical radiation emergency. Health Phys. 2007;93(5, suppl)S187-S190.

9. Society of Nuclear Medicine and Molecular Imaging Web site. Curriculum guide for educational programs in nuclear medicine technology. 4th ed. http://interactive. snm.org/docs/SNMTS_Curriculum_Guide_4th_Ed.pdf. Published August 25, 2008. Accessed July 18, 2013.

10. Becker SM. Learning from the 2011 Great East Japan Disaster: insights from a special radiological emergency assistance mission. Biosecur Bioterror. 2011;9:394-404.

11. Becker SM, Middleton SA. Improving hospital preparedness for radiological terrorism: perspectives from emergency department physicians and nurses. Disaster Med Public Health Prep. 2008;2:174-184.

12. Errett NA, Barnett DJ, Thompson CB, et al. Assessment of medical reserve corps volunteers' emergency response willingness using a threat- and efficacy-based model. Biosecur Bioterror. 2013;11:29-40.

13. Hansson M, Rääf CL. Visualisation and quantification of lung content of radionuclides associated with nuclear and radiological emergencies. Radiat Prot Dosimetry. 2011;145:341-350.

14. U.S. Department of Health and Human Services Web site. Surveys and monitoring: general. 10 CFR \$20.1501. http://www.gpo.gov/fdsys/pkg/CFR-2012-title10-vol1/ xml/CFR-2012-title10-vol1-part20.xml\#seqnum20.1501. Published January 1, 2012. Accessed July 18, 2013.

15. U.S. Department of Health and Human Services Web site. Calibration of survey instruments. $10 \mathrm{CFR} \S 35.61$. http://www.gpo.gov/fdsys/pkg/CFR-2012-title10vol1/xml/CFR-2012-title10-vol1-part35.xml\#seqnum35.61. Published January 1, 2012. Accessed July 18, 2013.
16. U.S. Department of Health and Human Services Web site. Records of Radiation Survey Instrument Calibrations. 10 CFR \$35.2061. http://www.gpo.gov/fdsys/ pkg/CFR-2012-title10-vol1/xml/CFR-2012-title10-vol1-part35.xml\#seqnum35.2061. Published January 1, 2012. Accessed July 18, 2013.

17. Moysich KB, McCarthy P, Hall P. 25 years after Chernobyl: lessons for Japan? Lancet Oncol. 2011;12:416-418.

18. Tokonami S, Hosoda M, Akiba S, Sorimachi A, Kashiwakura I, Balonov M. Thyroid doses for evacuees from the Fukushima nuclear accident. Sci Rep. 2012;2:507.

19. Centers for Disease Control and Prevention Web site. Population monitoring in radiation emergencies: a guide for state and local public health planners. http:// emergency.cdc.gov/radiation/pdf/population-monitoring-guide.pdf. Published August 2007 (predecisional draft). Accessed July 18, 2013.

20. Federal Emergency Management Agency Web site. Contamination monitoring standard for a portal monitor used for radiological emergency response. http:// www.fema.gov/library/viewRecord.do?id=5804. Published March 1995. Accessed July 18, 2013.

21. Centers for Disease Control and Prevention Web site. Use of radiation detection, measuring, and imaging instruments to assess internal contamination from intakes of radionuclides. http://www.bt.cdc.gov/radiation/clinicians/evaluation/ index.asp. Accessed July 18, 2013.

22. U.S. Department of Health and Human Services Web site. How to perform a survey for radiation contamination. http://www.remm.nlm.gov/howtosurvey. htm. Updated March 6, 2013. Accessed July 18, 2013.

23. Kramer GH. Considerations in screening/measuring children with internal/external contamination. Radiat Prot Dosimetry. 2010;142:51-53.

24. U.S. Department of Health and Human Services Web site. Radiation emergency medical management home page. http://www.remm.nlm.gov. Accessed July 18, 2013. 